UCRL-JC-123289

PREPRINT

$$
\text { CONF. } 9606229--1
$$

\title{
Measurements of Laser Imprint by XUV Radiography Using an X-Ray Laser
}

D. H. Kalantar, L. B. DaSilva, S. Glendinning, F. Weber B. A. Remington, S. V. Weber, E. Wolfrum, M. H. Key, JUN 241996 D. Neely, N. S. Kim, J. S. Wark, J. Zhang, C. L. S. Lewis, A. McPhee, J. Warwich, A. Demir, J. Lin, R. Smith, OSTI G. J. Tallents, and J. P. Knauer

This paper was prepared for submittal to the 24th European Conference on Laser Interaction with Matter Madrid, Spain June 3-7, 1996

May 30, 1996
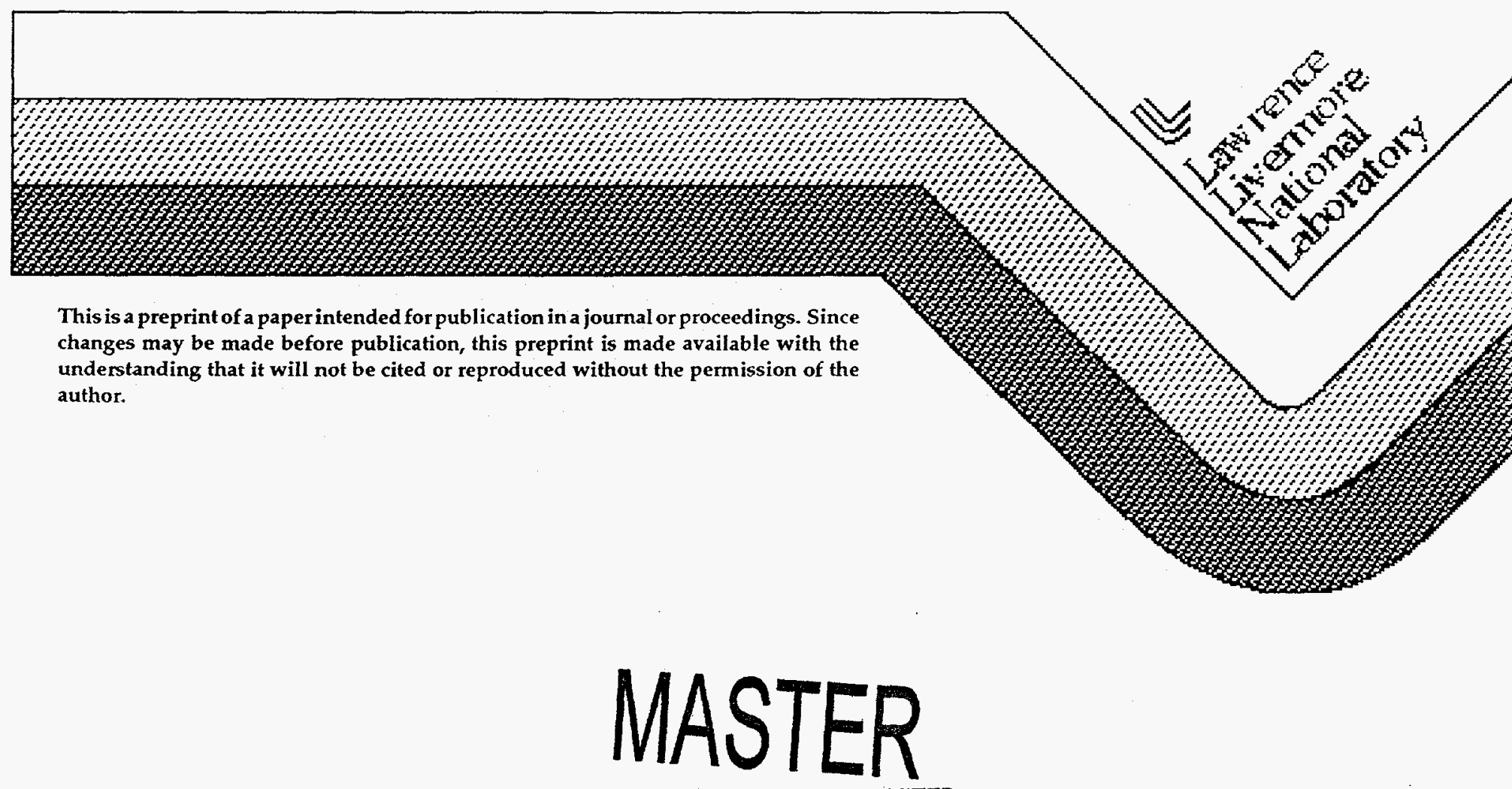


\section{DISCLAIMER}

This document was prepared as an account of work sponsored by an agency of the United States Government. Neither the United States Government nor the University of California nor any of their employees, makes any warranty, express or implied, or assumes any legal liability or responsibility for the accuracy, completeness, or usefulness of any information, apparatus, product, or process disclosed, or represents that its use would not infringe privately owned rights. Refenence herein to any specific commercial product, process, or service by trade name, trademark, manufacturer, or otherwise, does not necessarily constitute or imply its endorsement. recommendation, or favoring by the United States Government or the University of Califomia. The views and opinions of authors expressed herein do not necessarily state or reflect those of the United States Government or the University of Califomia, and shall not be used for advertising or product endorsement purposes. 


\title{
MEASUREMENTS OF LASER IMPRINT BY XUV RADIOGRAPHY USING AN X-RAY LASER
}

D. H. KALANTAR, L. B. DASILVA, S. G. GLENDINNING, F. WEBER, B. A. REMINGTON, S. V. WEBER, Lawrence Livermore National Laboratory, Livermore, CA, USA

E. WOLFRUM, M. H. KEY, D. NEELY

Rutherford Appleton Laboratory, Chilton, Didcot, Oxon, UK

N. S. KIM, J.S. WARK, J. ZHANG

Clarendon Laboratory, Department of Physics, University of Oxford, Oxford, UK

C. L. S. LEWIS, A. MCPHEE, J. WARWICK

Department of Pure and Applied Physics, Queens University of Belfast, Belfast, UK

A. DEMIR, J. LIN, R. SMITH, G. J. TALLENTS

Department of Physics, University of Essex, Colchester, UK

J.P. KNAUER

Laboratory for Laser Energetics, University of Rochester, Rochester, NY, USA

\begin{abstract}
We have developed a technique for studying the imprint of a laser bearn on a thin foil using an $\mathrm{X}$-ray laser as an XUV backlighter and XUV multilayer optics. This technique allows us to measure small fractional variations in the foil thickness due to hydrodynamics imprinted by direct laser irradiation. We present results of imprinted modulation and growth due to a low intensity 0.53 $\mu \mathrm{m}$ drive beam incident on a $2 \mu \mathrm{m}$ Al foil using a germanium $x$-ray laser at the Vulcan facility. We present measurements of the modulation due to static RPP, SSD smoothed, and ISI smoothed speckle patterns at $0.53 \mu \mathrm{m}$ irradiation.
\end{abstract}

In direct drive Inertial Confinement Fusion, high intensity laser beams directly irradiate the outside of a hollow spherical capsule that contains a layer of solid fusionable D-T in it inner surface. For ignition scale targets, the laser pulse starts at low intensity 'foot' at $10^{13} \mathrm{~W} / \mathrm{cm}^{2}$ for several nanoseconds before it builds up to more than $10^{15} \mathrm{~W} / \mathrm{cm}^{2}$ during the main drive portion of the pulse. Laser heating of the capsule surface results in an ablation pressure that accelerates the capsule shell radially inward in a spherical implosion. During this acceleration, perturbations due to surface roughness and due to imprint from spatial non-uniformities in the laser irradiation undergo Rayleigh-Taylor growth, potentially severely degrading performance. 
We have used an $x$-ray laser for XUV radiography to characterize the modulations in optical depth of a thin foil due to laser imprint and subsequent Rayleigh-Taylor growth. Preliminary experiments were done using an yttrium $x$-ray laser backlighter on Nova to characterize the imprint due to $0.35 \mu \mathrm{m}$ laser irradiation of a $3 \mu \mathrm{m}$ Si foil ${ }^{1,2.3}$. We have extended these experiments using a Ge x-ray laser backlighter on the Vulcan laser. We characterized the imprint and subsequent RayleighTaylor growth of modulations due to $0.53 \mu \mathrm{m}$ laser irradiation of a $2 \mu \mathrm{m}$ thick Al foil at $2-8 \times 10^{12} \mathrm{~W} / \mathrm{cm}^{2}$. In this paper we describe some results from the experiments conducted at the Vulcan laser facility.

\section{XUV Radiography of laser imprint}

We generated a Ge J=0-1 x-ray laser at $19.6 \mathrm{~nm}$ using six beams of the Vulcan laser. We placed a thin $(2 \mu \mathrm{m})$ Al foil about $3 \mathrm{~cm}$ from the output of the Ge $x$-ray laser. We then used two multilayer mirrors to image the AI foil in the $x$-ray laser wavelength onto an XUV sensitive CCD; a $1 \mathrm{~m}$ spherical mirror at near normal incidence, and a flat mirror at $45^{\circ}$ incidence, as shown in Figure 1. The spherical mirror was placed $53 \mathrm{~cm}$ from the $\mathrm{Al}$ foil, providing a 16X magnified image of the foil on the $\mathrm{CCD}$, and the $45^{\circ}$ angle of incidence planar mirror was used to relay the image onto the $\mathrm{CCD}$ and spectrally isolate the image from the thermal background noise.

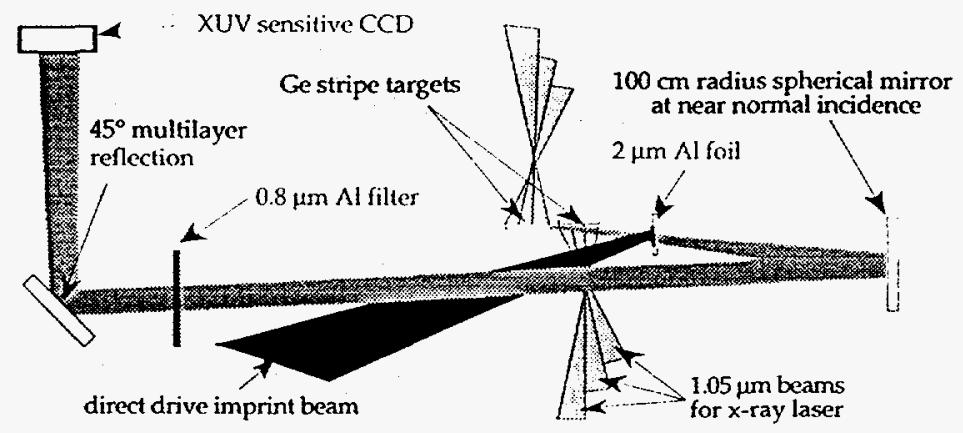

Figure 1: Geometry for the X-ray laser target and XUV imaging system used to measure the modulation in optical depth of a thin Al foil due to direct drive laser imprint.

We used a single Vulcan laser beam with a static random phase plate speckle pattern, SSD smoothed speckle pattern, and ISI smoothed speckle pattern to imprint on the Al foil. We characterized the imprinted modulation as a function of time with the different smoothing schemes. 


\section{Results and Discussion}

In Figure 2, we show optical far field images of the single beam laser focal spot used in these experiments. This figure shows intensity modulation of a) a static RPP speckle pattern, b) a 1-D SSD smoothed speckle pattern, and c) for an ISI smoothed RPP speckle pattern.

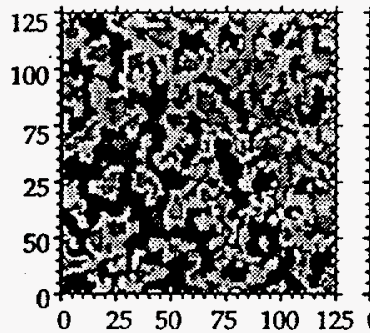

a) Static speckle

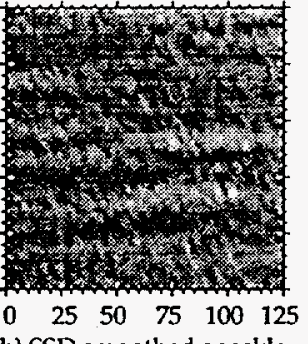

b) SSD smoothed speckle

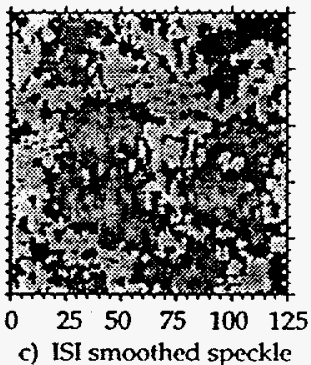

c) ISI smoothed speckle

Figure 2: Far field images of the laser focal spot. The scale is in microns at the target.

We irradiated the $2 \mu \mathrm{m}$ thick $\mathrm{Al}$ foils directly by an intensity of 3$8 \times 10^{12} \mathrm{~W} / \mathrm{cm}^{2}$ of $0.53 \mu \mathrm{m}$ laser light using the three speckle patterns, and we recorded the modulation in optical depth in the foil due to laser imprint and subsequent Rayleigh-Taylor growth using the Ge x-ray laser backlighter. We show XUV radiographs of the modulation in optical depth in the $\mathrm{Al}$ foil in Figure 3, recorded at 0.2 ns into the laser pulse.

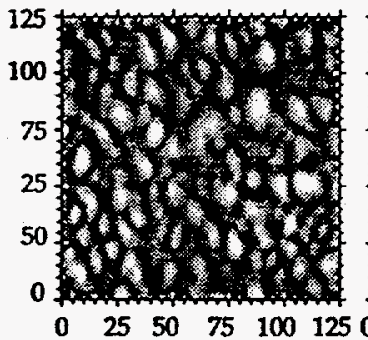

a) Static speckle

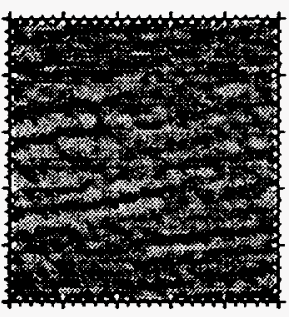

b) SSD smoothed speckle

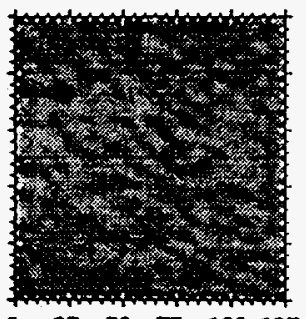

c) ISI smoothed speckle

Figure 3: Modulation in optical depth of an Al foil irradiated by a) a static RPP speckle pattern, b) a 1-D SSD smoothed speckle pattern, and c) an ISI smoothed speckle pattern, all at $0.53 \mu \mathrm{m}$.

Power spectra for the imprinted modulation measured in these images are shown in Figure 4. The integrated RMS modulations in optical depth we measured from these XUV radiographs were $0.37,0.17$, and 0.20 . The RMS measured from undriven $\mathrm{Al}$ foil targets was about 0.13 . This corresponds to a surface roughness of about $60 \mathrm{~nm}$ on the $\mathrm{Al}$ foil. 
We show the RMS modulation in optical depth as a function of time recorded by XUV radiography in Figure 5. This figure shows that the modulation imprinted due to a static speckle pattern grows faster than for a smoothed speckle pattern. The SSD smoothed case shows a strong reduction in the modulation, but it still grows late in time. The ISI smoothed beam, however, does not show significant growth at any time up to $0.8 \mathrm{~ns}$.
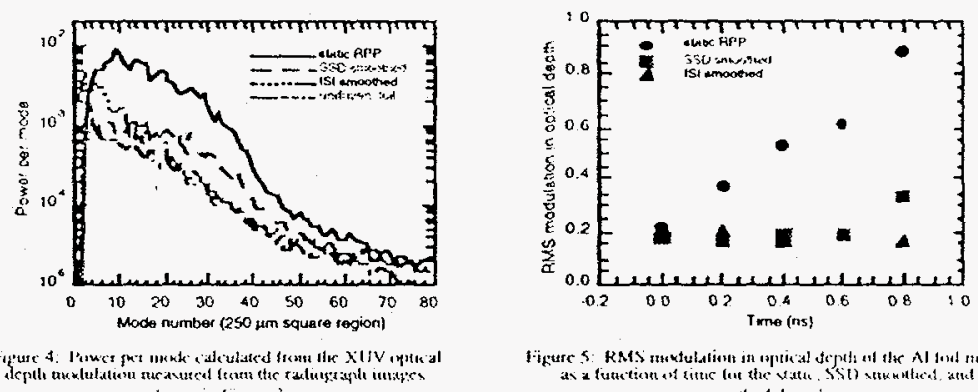

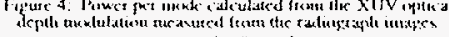

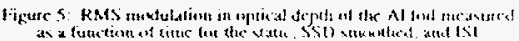
Nhun in tigrate?

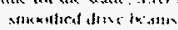

\section{Summary}

We demonstrated measurements of the modulation imprinted by low intensity $0.53 \mu \mathrm{m}$ irradiation of a thin $A l$ foil using the $G_{x} x$-ray laser at the Vulcan laser facility. We measured the imprinted modulation and subsequent Rayleigh-Taylor growth in the foil as a function of time with various laser smoothing schemes.

\section{Acknowledgements}

This work was partially supported by the Lawrence Livermore National Laboratory under the auspices of the U.S. DOE under Contract No. W7405-ENG-48. EW was supported by the Austrian Fonds zur Förderung der wissenschaftlichen Forschung under Project No. P10844 NAW.

\section{References}

${ }^{1}$ M. H. Key et al, J. Quant. Spectrosc: Radiat. Transfer 54, 221 (1995).

2 D. H. Kalantar et al, Rev. Sci. Instrum. 67, 781 (1996).

${ }^{3}$ D. H. Kalantar et al, Phys Rev. Letters 76, 3574 (1996). 


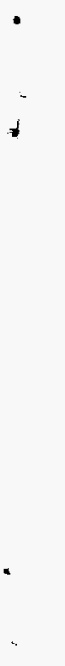

$y$

.

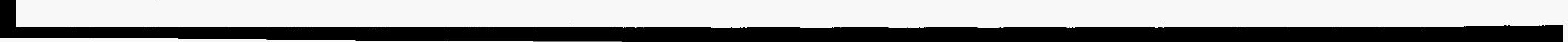



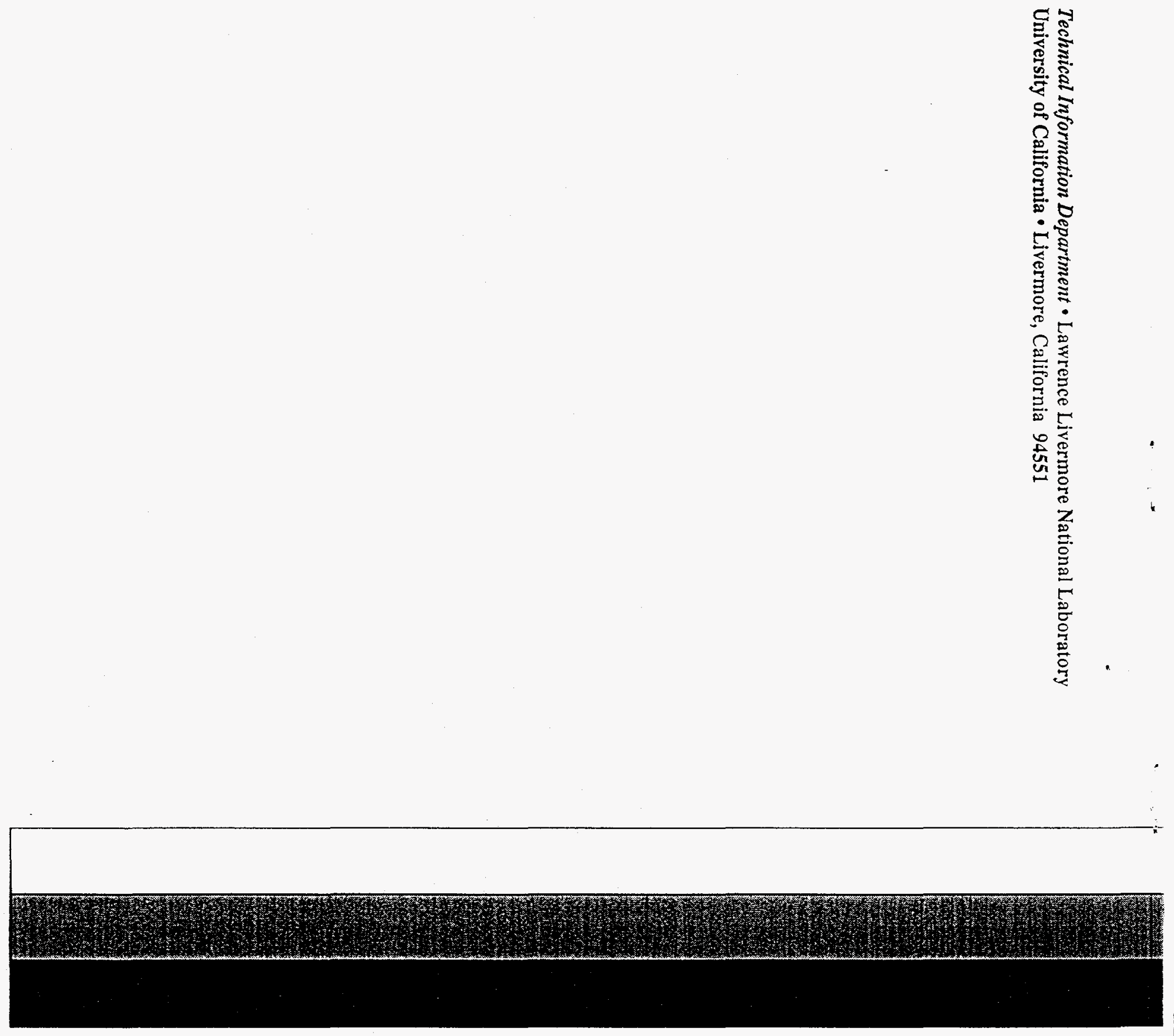